\title{
1 Global patterns in marine predatory fish
}

2

3 P. Daniël van Denderen ${ }^{1 *}$, Martin Lindegren ${ }^{1}$, Brian R. MacKenzie ${ }^{1}$, Reg A. Watson ${ }^{2,3}$ and Ken

4 H. Andersen 1

5

$6{ }^{1}$ Centre for Ocean Life, National Institute of Aquatic Resources, Technical University of Denmark,

7 Kemitorvet B-202, 2800 Kongens Lyngby, Denmark

$8 \quad{ }^{2}$ Institute for Marine and Antarctic Studies, University of Tasmania, GPO Box 252-49, Hobart, TAS,

97001 , Australia

$10{ }^{3}$ Centre for Marine Socioecology, University of Tasmania, Hobart, Tasmania, 7004, Australia 11 
Large teleost (bony) fish are a dominant group of predators in the oceans constituting a major source of food and livelihood for humans. These species differ markedly in morphology and feeding habits across oceanic regions; large pelagic species such as tunas and billfish typically occur in the tropics, whereas demersal species of gadoids and flatfish dominate boreal and temperate regions. Despite their importance for fisheries and the structuring of marine ecosystems, the underlying factors determining the global distribution and productivity of these two groups of teleost predators are poorly known. Here we show how latitudinal differences in predatory fish can essentially be explained by the inflow of energy at the base of the pelagic and benthic food chain. A low productive benthic energy pathway favours large pelagic species, whereas equal productivities support large demersal generalists that outcompete the pelagic specialists. Our findings demonstrate the vulnerability of large teleost predators to ecosystemwide changes in energy flows and hence provide key insight to predict responses of these important marine resources under global change.

Marine top predators influence the structure and dynamics of food webs by imposing mortality and behavioural changes on prey and by feeding on parallel pathways of energy from both the pelagic (open water) and the benthic (bottom) zone of the ocean ${ }^{1-3}$. Many of these predator species have declined in population sizes and distribution ranges, which in several cases has resulted in large-scale changes in ecosystems, involving trophic cascades ${ }^{2-4}$.

Large teleost fish are a dominant group of predators in the global oceans, support lucrative commercial and recreational fisheries and provide food for human populations worldwide ${ }^{5-7}$. These predators clearly differ in morphology and feeding habits across the world. In tropical and subtropical regions, teleost predators are often fast, mobile species that feed within the pelagic zone ${ }^{8,9}$, while in boreal and 
temperate regions the largest teleost species are typically slower growing, demersal (bottom-living) ${ }^{10}$ and adapted to feeding on both pelagic and benthic organisms ${ }^{6,11-14}$. Despite their importance for structuring marine ecosystems and their significant socio-economic value, the underlying factors determining the global distribution and productivity of these two groups of marine predatory fish are poorly known. Here we test the specific hypothesis that spatial patterns in the distribution and productivity of these groups are primarily driven by pronounced global differences in the productivity of a pelagic and a benthic energy pathway in marine food webs worldwide (Fig. 1).

We examine this hypothesis by assessing the relative productivity of large marine teleost fishes using global fisheries landings data ${ }^{15}$ across 232 marine ecoregions ${ }^{16}$. For each ecoregion, we calculate the average proportion of large pelagic vs demersal fish landings between 1970 and 2014. We show that in this case, the proportion of landings represents a good estimate of the dominant predatory feeding strategy in the sea. We develop a food-web model with two energy channels, one pelagic and one benthic, to formally test our hypothesis and to predict the biomass fraction of pelagic vs demersal predatory fish worldwide.

\section{Results}

The proportion of large pelagic and demersal teleost predators varied strongly in fisheries landings across the globe (Fig. 2). As expected, large pelagic fish dominate in the tropics and subtropics, while large demersal fish prevail in temperate and polar regions in both hemispheres. Despite the pronounced latitudinal gradients, some areas in the tropics have a relatively low proportion of large pelagic fish (e.g. Gulf of Mexico, Brazilian shelf), primarily due to high landings of demersal fish species; e.g. the highly abundant largehead hairtail (Trichiurus lepturus). 
Whether landings data can predict biomass (and as such the dominant predatory fish feeding strategy in the sea) has been disputed ${ }^{17}$. Here, we use weight fractions in landings and do not predict absolute biomass. Nevertheless, average landings and biomass ${ }^{18}$ are highly correlated for 71 pelagic and demersal predatory fish stocks (Supplementary Fig. 1, p-value $<0.001, \mathrm{r}^{2}=0.78$ ). The weight fraction in landings also corresponds well to the fraction in biomass over time, based on assessed pelagic and demersal fish stocks ${ }^{18}$ from nine different large marine ecosystems (LMEs) (Supplementary Fig. 2, pvalue $\left.<0.001, \mathrm{r}^{2}=0.91\right)$. Proportions of pelagic and demersal fish landings weighted with the economic value of $\operatorname{species}^{19}$ (i.e. a crude measure of potential fisheries preferences) demonstrate a similar global pattern (Supplementary Fig. 3, p-value $<0.001, r^{2}=0.97$ ), highlighting that price differences between both groups are overshadowed by the considerably larger differences in the weight of the landings of the two groups. Further robustness checks show that the global patterns remain highly similar if large elasmobranches are included in the analysis (Supplementary Fig. 4, p-value $<$ $0.001, \mathrm{r}^{2}=0.98$ ) or illegal, unregulated and unreported (IUU) catches and discards ( $\mathrm{p}$-value $<0.001, \mathrm{r}^{2}$ $=0.99$ ). The robustness of our result to the potential biases described above provide strong support for using the weight fraction of pelagic vs demersal fish based on global landings as our response variable to estimate the dominant predatory fish feeding strategy in the sea.

We hypothesize that the relative production of pelagic and demersal predatory fish is dependent on the differences in inflow of energy at the base of the pelagic and benthic pathway (Fig. 1). Most of the ocean net primary production (NPP) occurs in the pelagic layer. Yet, in some regions, sufficient carbon reaches the bottom via sinking and other active transport processes to support high production of benthic organisms. There are multiple environmental conditions that can influence the downward flux of carbon to the seafloor. First, there is a clear relation with bathymetry, as in deeper oceans only a 
77 fraction of the production from the pelagic zone may reach the seabed ${ }^{20}$. The proportion of NPP which

reaches the bottom also varies with latitude. This happens because low water temperatures decelerate remineralization processes and subsequently increase the proportion of NPP available for export ${ }^{21,22}$, but also because seasonal variability in NPP may result in a temporal mismatch between phytoplankton and zooplankton production leading to a larger fraction of (ungrazed) NPP sinking to the bottom during the spring bloom in seasonal environments ${ }^{23}$. Finally, it has been suggested that the proportion of NPP sinking to the seabed is dependent on the depth of the photic zone and either total NPP or chlorophyll concentration ${ }^{24}$.

We approximated the difference in pelagic and benthic production by calculating the ratio between the fraction of NPP that remains in the photic zone $\left(F_{\text {photic }}\right)^{24}$ versus the fraction of NPP that reaches the seabed $\left(F_{\text {seabed }}\right)$ (see Supplementary Fig. 5$)$. Using non-linear regression models, we found that the ratio between $F_{\text {photic }}$ and $F_{\text {seabed }}$ explains a substantial part of the global variability in the proportion of large pelagic vs demersal fish landings (Fig. 3, deviance explained $=68 \%$, p-value $<0.001$; see other environmental predictors in Supplementary Table 1). The results show how in most tropical and subtropical areas a highly productive pelagic energy pathway favours large pelagic fish, while in many temperate and polar regions more equal productivities of the two pathways favour large demersal fish (feeding as a generalist on both pelagic and demersal resources).

In order to further test our hypothesis, we developed a food-web model with two energy channels to predict the biomass fraction of large pelagic species across ecoregions (Fig. 1 and Supplementary Table 2-3). The pelagic and benthic energy pathways are modelled as two separate channels that have their own resource carrying capacity. The carrying capacity of the pelagic resource is calculated by multiplying a total resource carrying capacity constant $\left(R_{\max }\right)$ with $F_{\text {photic }}$, the carrying capacity of the 


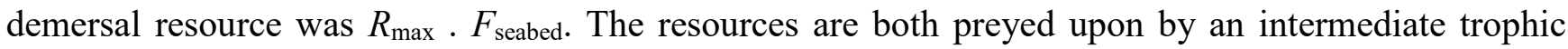
level, representing smaller fishes and invertebrates, while two groups of predators are included at the top of the energy pathways; a pelagic specialist feeding exclusively on a pelagic diet, and a demersal generalist feeding on both energy pathways.

The food-web model predicted global patterns in pelagic vs demersal predators largely corresponding to the proportions of large pelagic fish derived from landings (Fig. $\left.4 a-b, r^{2}=0.58\right)$. However, some areas showed a strong mismatch between model predictions and landings data (Fig. 4b-c). Interestingly, the largest differences can be observed at high latitudes in the Southern Ocean and the temperate North Pacific where the model predicts a higher production of pelagic specialists compared to the proportions derived from landings. We expect that the model predictions are realistic because large pelagic predators are indeed present and highly abundant in many of these areas. However, not as predatory fish but as fast, pelagic-feeding endotherms that maintain a high body temperature and activity despite the cold waters. For example, the Aleutian Islands, Kamchatka shelf, Antarctica and South Georgia (Fig. 4c, red areas) harbour high biodiversity and densities of penguins and pinnipeds ${ }^{25-27}$. While this lends support to our model predictions, we stress the need for further research on the complementary roles of marine endo- and ectotherm predators in relation to temperature and the productivity of the pelagic and benthic energy pathway. There is also a mismatch in ecoregions in the tropics where the model predicts higher production of demersal generalists compared to the proportions in landings (Fig. $4 c$, blue areas). In these regions, the energy fluxes to the seabed are predicted to be relatively high (Supplementary Fig. 5), thereby potentially supporting a high production of demersal generalists. The high fraction of NPP predicted to reach the seabed is consistent with other studies, using alternative methods, to predict the carbon flux to the seabed on a global scale ${ }^{23}$. In many of these areas, relatively 
121 high catch rates of sharks and rays can be observed ${ }^{15}$, species that are often demersal generalists and as

122 such similar to demersal teleost predators. Although the contribution of large sharks and rays to overall

123 fisheries landings is marginal (Supplementary Fig. 4), potentially the result of long-term overfishing ${ }^{28}$,

124 including elasmobranch predators in the analysis increases the amount of demersal generalists

125 substantially near Australia, Peru and Chile in areas where the model predicts higher production of

126 demersal generalists compared to the proportions in landings (Fig. 4c, Supplementary Fig. 4). An

127 alternative explanation for the lower proportion of demersal generalists in the landings can be due to

128 the ability of pelagic predators to disperse widely ${ }^{9}$ and as such dampen local differences in fish 129 abundances of the two predatory groups that have originated from variation in the energy flux to the 130 seabed.

\section{Discussion}

132 Our study supports the hypothesis that the inflow of energy at the base of the pelagic and benthic channel determines the dominant feeding strategy of large teleost predatory fishes. Pelagic specialists dominate when energy is primarily channelled through the pelagic pathway, while demersal generalists outcompete the specialists when both pelagic and benthic resources are available. This explanation assumes that demersal generalists' niches and diets overlap with pelagic specialists because they exploit both benthic and pelagic resources. Overlapping diets have indeed been observed in areas where both groups of species co-occur ${ }^{11,29,30}$. Further, overlapping diets may occur even in the absence of direct spatial overlap between the predator groups, due to pronounced habitat shifts of pelagic prey species through daily (vertical) and seasonal (onshore-offshore) migrations (e.g. ${ }^{31,32}$ ). Since both large

141 pelagic and demersal predators may access and feed on these highly mobile prey, but at different times, 142 in different areas and even on different life stages, they engage in exploitative competition. Niche 
143 overlap will be lower in deep sea environments where demersal species are less able to exploit pelagic

144 resources. Even though reduced niche overlap in deep sea environments is not explicitly represented in 145 our model or data analysis, it is implicitly captured because the fluxes are typically low in deep sea 146 areas and consequently pelagic specialists are dominating. Although the degree of dietary overlap and 147 the strength of competition between pelagic and demersal predators at a global scale are poorly known, 148 our results suggest that competition between pelagic and demersal feeding strategies exists. 149 Consequently, a decline in the productivity of the benthic energy pathway will shift dominance towards 150 pelagic specialists (and vice versa).

151 We assumed that large pelagic teleost fish are superior in exploiting the pelagic resource compared to 152 large demersal species. Large pelagic fish are highly adapted to feeding on fast-moving pelagic 153 resources (such as forage fish) and have developed specific morphological features (e.g. high muscle 154 protein, large gill surface area and the warming of muscles) to support an active pelagic lifestyle ${ }^{33,34}$. 155 Such physiological and morphological adaptations can explain the superiority of pelagic specialists to 156 feed on pelagic prey compared to the more "sluggish" demersal generalists. Yet, we lack knowledge to 157 explicitly account for the energetic costs associated with these physiological and morphological 158 adaptations ${ }^{33}$ in a food-web model, and also, to account for the costs of finding, capturing and digesting 159 prey for both groups of species. Despite the uncertainty about the specific nature of the trade-off 160 between the pelagic and demersal lifestyles, it seems likely that pelagic predators are more specialized 161 upon pelagic prey, and thus superior to the demersal fish while feeding on this resource.

162 When top predators feed on both pelagic and benthic prey resources, they act as couplers of these 163 energy pathways. This coupling may infer stability to the food web if the predators balance the strength 164 of their feeding interactions on pelagic and benthic prey with the relative difference in productivity 
165 (and turnover rates) of the pathways ${ }^{1}$. We argue that not all predatory fish act as such "balanced" 166 couplers, as species can be specialized on exploiting pelagic resources. The specialization implies that 167 ecosystem-level variations in the productivity of the pelagic and benthic energy pathways will not only 168 affect the occurrence and productivity of large predatory fishes, but also the stability of the ecosystem.

169 There is large uncertainty related to current predictions of future fish and fisheries production, 170 primarily since it is unclear how climate change will affect ocean primary production and how energy 171 will be transferred to the upper trophic levels of marine ecosystems ${ }^{35,36}$. Our findings suggest that 172 changes in the global occurrence and productivity of large predatory fishes can be anticipated by 173 understanding how climate change will affect the base of pelagic and benthic food chains. Changes in 174 the productivity of these energy pathways in response to climate change are expected ${ }^{37,38}$ and, in some 175 instances, already observed, e.g. large-scale changes in phytoplankton abundance and ocean primary 176 production $^{39,40}$. For most continental shelf areas, climate change has been predicted to decrease detritus 177 fluxes to the seafloor ${ }^{35}$, thereby potentially limiting large demersal fish abundances and fisheries 178 production. Accounting for the changes in the pelagic and demersal energy pathways is therefore key to 179 reliably predict the effects of climate change on the upper trophic levels of marine ecosystems, and the 180 impact on supported fisheries. 
182 Global fisheries data

183 We used global fisheries landings data ${ }^{15}$ to determine general patterns in feeding strategies of marine predatory fish between 1970 and 2014. The spatial fisheries landings data is predominately from global fisheries catch statistics assembled by the Food and Agriculture Organization of the United Nations (FAO) and complemented by statistics from various international and national agencies. These datasets, with higher spatial resolution, were nested into the broader FAO regions, replacing the data reported at the coarser spatial resolution. The global fisheries landings data was mapped to 30-min spatial cells using information on the distribution of reported taxa and fishing fleets ${ }^{15}$. For the purpose of this study, we aggregated the data and examined fisheries landings data on a marine ecoregion scale ${ }^{16}$.

\section{$191 \quad$ Feeding strategies of marine fish}

192 To examine the productivity of marine teleost fish along the pelagic and benthic energy pathways, we classified fish into two general feeding strategies, either feeding exclusively on the pelagic pathway (pelagic fish) or (partly) relying on the benthic pathway for feeding (demersal fish). This was done using the functional group classification system developed in the Sea Around Us (SAU) project ${ }^{41}$. Data classified using the SAU project as shark, ray, any type of invertebrate or bathydemersal and bathypelagic fish (these groups include the mesopelagic fish) were removed (see Supplementary Table 4). This limited our analysis to teleost fish and the two dominant feeding strategies. The two feeding strategies were further divided on the basis of fish maximum size ${ }^{42}$. Large predatory species were classified as fish with a maximum size $\geq 90 \mathrm{~cm}$. The choice of this maximum size limit did not affect our analysis as it can range from $70-150 \mathrm{~cm}$ without changing the results (Supplementary Fig. 6). Part 
203 these observations were excluded. Other data are identified at too general a taxonomic grouping to 204 derive the correct size-class (e.g. Gadiformes, Gadidae) and these landings data were assumed to 205 represent species with smaller maximum sizes than $70 \mathrm{~cm}$.

206 For each of the ecoregions, we calculated the average weight fraction of pelagic fish compared to 207 demersal fish in the fisheries landings data between 1970 and 2014. This was only done for ecoregions 208 where at least $60 \%$ of the landings data (in tonnes) could be classified into one of the functional groups 209 from the SAU project (but note that the main findings are unaffected when more or less strict criteria 210 for ecoregion selection are chosen). All fractions were averaged over at least 24 years of data (for 219 211 ecoregions fractions were averaged over 45 years of data).

212 Besides the large predatory teleost fish, we also determined whether there were general patterns in 213 feeding strategies of teleost fish species with a maximum size $<90 \mathrm{~cm}$ (Supplementary Fig. 7). The 214 results show there is no clear latitudinal pattern and no relationship between the small pelagic fish 215 fraction and $\mathrm{F}_{\text {photic }} / \mathrm{F}_{\text {seabed. }}$ The pattern is not improved when pelagic and benthic invertebrate landings 216 are included in the analysis (Supplementary Fig. 7).

\section{Potential bias due to the use of fisheries landings}

218 Our assessment of the global variation in the large predatory fish may be biased by our use of global 219 fisheries landings data instead of biomass data. We included a variety of analyses to examine this 220 potential bias. We first examined with available stock assessments from the RAM Legacy Stock 221 Assessment database ${ }^{18}$, the relationship between catch and biomass of large teleost fish. For this 222 analysis, data was available for 71 different large predatory fish stocks (38 pelagic and 33 demersal, 223 Supplementary Table 5). For each stock, we averaged both total biomass and total catch for all years 224 with assessment data and examined across stocks the relationship between average biomass and catch 
and whether this differs between both feeding groups (model comparison using AIC scores).

226

227

228

229

230

231

232

233

234

235

236

237

238

239

240

241

242

243

244

245

246

247

Afterwards, we tested the relationship between the weight fraction of pelagic fish versus demersal fish in catch and biomass over time. This was done by selecting pelagic and demersal fish in all size groups from the RAM stock assessment database ${ }^{18}$ for nine different Large Marine Ecosystems (LMEs) over multiple years. The LMEs and years are selected since they have data available on assessed fish stocks in both feeding strategies (see Supplementary Table 6). To further check robustness of our findings, we examined how much the fraction large pelagic and demersal fish varied when the fraction is corrected for the economic value of the species (assuming that species are preferred by fisheries when they have higher economic value). Nominal economic value, standardized per unit weight, were derived for each species and year from Sumaila et al. ${ }^{19}$, and were used to estimate the economic value of both feeding groups (standardized per unit weight) per ecoregion and year. When multiple species from the same feeding group were present in the landings in a particular ecoregion and year, the economic value of that feeding group was averaged by weighting all species with the landings. Afterwards, we calculated the price difference between pelagic and demersal fish for each year and ecoregion and averaged this across all years per ecoregion. A price-corrected weight fraction large pelagic fish was then calculated by: wf . (1-pf) / (wf . (1-pf) + (1-wf) . pf), where wf is the weight fraction large pelagic fish from fisheries landings and pf is the price fraction (a fraction of 0.9 means that pelagic fish are 9 times more valuable than demersal fish at similar tonnes of landings) (Supplementary Fig. 3). We also examined how the inclusion of large sharks and rays (taken from the fisheries landings database ${ }^{15}$ ) affected the global patterns in predatory fish. Classification of pelagic (oceanic) sharks and rays followed ${ }^{43}$, all other taxa were classified as demersal generalists (maximum body size is based on ${ }^{42}$ ). Finally, we examined how estimates of illegal, unregulated and unreported (IUU) catches and discarded fish affected our calculation of the weight fraction of large pelagic vs demersal fish. Estimates of IUU 
248 catches and discarded fish were taken from the spatial fisheries landings database ${ }^{15}$ per ecoregion and 249 year.

$250 \quad$ Pelagic and benthic energy production

251 We hypothesized that the relative production of pelagic and demersal fish in fisheries landings across 252 ecoregions is dependent on the differences in pelagic and benthic production. We approximated the 253 difference in production by calculating the ratio between the fraction of NPP that remains in the photic 254 zone $\left(F_{\text {photic }}\right)$ versus the fraction of NPP that sinks to the seabed $\left(F_{\text {seabed }}\right)$. This was done by first 255 calculating the fraction of NPP that sinks out of the photic zone (pe-ratio) and secondly by accounting 256 for energy loss between the depth of the photic zone and the seabed.

257 We used an empirical relationship introduced by Dunne et al. ${ }^{24}$ to calculate the pe-ratio. This 258 relationship captures $\sim 60 \%$ of observed global variation in pe-ratio using field-derived estimates of sea 259 surface temperature (SST), primary production (NPP) and the photic zone depth (Zeu). In this 260 calculation, increased temperature reduces the pe-ratio, while it is increased with increasing primary 261 production and a smaller photic zone depth: pe-ratio $=-0.0101 \mathrm{SST}+0.0582 \ln \left(\frac{\mathrm{NPP}}{\mathrm{Zeu}}\right)+0.419$. To 262 263 estimate the pe-ratio on a global scale with the empirical model, we used average annual sea surface $\begin{array}{llllll}\text { temperature } & \text { (degrees } & \text { Celsius) } & \text { between } & 1998 & \text { and }\end{array}$ 264 (http://www.esrl.noaa.gov/psd/data/gridded/data.noaa.oisst.v2.html), average daily net primary 265 production ( $\mathrm{mg} \mathrm{C} / \mathrm{m}^{2} /$ day) from the Vertically Generalized Production Model (VGPM) using 266 MODIS data between 2003 and 2008 (http://www.science.oregonstate.edu/ocean.productivity) ${ }^{44}$ and 267 we approximated the photic zone depth from average daily surface chlorophyll-a concentrations (mg $268 \mathrm{Chl} / \mathrm{m}^{3} /$ day) from the Sea-viewing Wide Field of view Sensor (SeaWiFS) between 1998 and 2008 269 (http://oceancolor.gsfc.nasa.gov/cms) (following ${ }^{45}$, see for original description ${ }^{46}$ ). The sea surface 
temperature data was resampled to a $1 / 12$ degrees grid to be able to use more detailed information on

271 spatial variation in bathymetry. The derived pe-ratios varied across the globe between 0.04 and 0.74

272 and were used to calculate $F_{\text {photic }}$ (Supplementary Fig. 5), the predicted fraction of NPP that remains in 273 the photic zone:

274

$$
F_{\text {photic }}=1-r \text {, }
$$

275 where $r$ is the pe-ratio.

276 The fraction of NPP that sinks out of the photic zone is reduced in energetic content before it reaches

277 the seabed, especially in deeper oceans where only a fraction of the production from the pelagic zone 278 may reach the seabed. To account for this effect, we accounted for energy loss, adjusting a function 279 described in ${ }^{47}$ :

280 For all grid cells where the seabed depth is equal or shallower than depth of the photic zone:

281

$$
F_{\text {seabed }}=\text { pe-ratio, }
$$

282

all other grid cells:

$$
F_{\text {seabed }}=\text { pe-ratio }(\text { seabed depth / depth photic zone })^{-0.86}
$$

Bathymetric data (m) was extracted per 1/12 degrees grid from the ETOPO1 Global Relief Model with 285 sea ice cover $^{48}$.

286 The calculated fluxes in the pelagic and benthic zone only provide a first-approximation of the relative 287 productivity of the pathways. The estimates ignore different aspects well-known to influence pelagic 288 and benthic energy pathways, such as the role of benthic primary producers, which especially in 
289 coastal waters contribute to a large part of the overall production ${ }^{49}$, areas with high subsurface 290 productivity, where NPP is underestimated when using satellite-derived NPP products ${ }^{50,51}$, and any 291 active transport processes to the seafloor ${ }^{52,53}$. Despite these limitations, the predicted large-scale spatial 292 variation in $F_{\text {photic }}$ and $F_{\text {seabed }}$ (Supplementary Fig. 5) seems to be consistent with other studies, using 293 alternative methods ${ }^{23,54}$.

294 Data aggregation per ecoregion and data analysis

295 Both $F_{\text {photic }}$ and $F_{\text {seabed }}$ were averaged per ecoregion. To account for latitudinal differences in grid size 296 all $F_{\text {photic }}$ and $F_{\text {seabed }}$ values per ecoregion were weighted with respect to latitude (weighting factor $=$ $297 \cos (\pi / 180 \cdot$ degrees latitude) $)$ following ${ }^{55}$. Besides, as fish production is expected to be highest in areas 298 with high primary production ${ }^{56}$, we also weighted $F_{\text {photic }}$ and $F_{\text {seabed }}$ per ecoregion with respect to grid 299 cell differences in NPP.

300 Relationships between the fraction of pelagic fish and the ratio between $F_{\text {photic }}$ and $F_{\text {seabed }}$ were 301 examined using generalized additive models with a beta distribution (continuous probability 302 distribution between 0 and 1) and (after model fit inspection) with a cauchit link function. The ratio between $F_{\text {photic }}$ and $F_{\text {seabed }}$ was $\log _{10}$ transformed, while the pelagic fish fraction was transformed to 304 avoid zeros and ones following ${ }^{57} ; \mathrm{y}=(\mathrm{y}(\mathrm{n}-1)+0.5) / \mathrm{n}$, where $\mathrm{y}$ is the pelagic fish fraction and $\mathrm{n}$ the 305 number of ecoregions. Maps were produced using rworldmap ${ }^{58}$.

\section{$306 \quad$ Food-web model}

307 Following the results of the fisheries data analyses, a food-web model was developed to study the competitive interactions between large pelagic specialists and demersal generalists across marine ecoregions. The benthic and pelagic energy pathways were modelled as two separate channels that 
310 have their own resource carrying capacities with semi-chemostat dynamics. The carrying capacity of

311 the pelagic resource $\left(K_{p}\right)$ was calculated by multiplying the total resource carrying capacity $\left(R_{\max }\right)$ with

$312 F_{\text {photic }}$, the carrying capacity of the demersal resource $\left(K_{B}\right)$ was $R_{\max } . F_{\text {seabed }}$ (see for model formulation

313 Supplementary Table 2). The resources were both preyed upon by an intermediate trophic level, while

314 two predatory species were included at the top of the energy pathways (following Fig. 1).

315 We hypothesized that large pelagic teleost fish are superior in exploiting the pelagic resource compared 316 to large demersal species (see for arguments the second paragraph in the discussion section). To 317 incorporate this in the model, feeding as a generalist comes at a cost and this cost was implemented 318 with a lower attack rate of the generalist, meaning that the specialist is superior in exploiting the 319 pelagic resource. The value of the attack rate parameter was selected to obtain (approximately) an equal 320 amount of ecoregions that either overestimated the amount of pelagic or demersal fish compared to 321 fisheries landings. It resulted in an attack rate of the generalist that is 0.8 of the attack rate of the 322 specialist. This value can be varied between 0.65 and 0.95 without changing the $r^{2}$ of the statistical 323 relationship between landings data and model output with $4 \%\left(\mathrm{r}^{2}\right.$ is $58 \%$ when a value of 0.8 is used, 324 see Fig. 4).

\section{Data availability:}

326 A table is available as supplementary data with information per ecoregion on the fraction pelagic fish in 327 landings, environmental variables and the food-web model outcome. Detailed global fisheries landings 328 data is available from Watson ${ }^{15}$. 
331 1. Rooney, N., McCann, K., Gellner, G. \& Moore, J. C. Structural asymmetry and the stability of 332 diverse food webs. Nature 442, 265-269 (2006).

333 2. Estes, J. A., Heithaus, M., McCauley, D. J., Rasher, D. B. \& Worm, B. Megafaunal impacts on structure and function of ocean ecosystems. Annu. Rev. Environ. Resour. 41, 83-116 (2016).

335 3. Heithaus, M. R., Frid, A., Wirsing, A. J. \& Worm, B. Predicting ecological consequences of 336 marine top predator declines. Trends Ecol. Evol. 23, 202-210 (2008).

337 4. Baum, J. K. \& Worm, B. Cascading top-down effects of changing oceanic predator abundances. J. Anim. Ecol. 78, 699-714 (2009).

5. FAO. The State of World Fisheries and Aquaculture 2016. Contributing to food security and nutrition for all. Rome. 200 pp. (2016).

341 6. Link, J. S., Bogstad, B., Sparholt, H. \& Lilly, G. R. Trophic role of Atlantic cod in the ecosystem. Fish Fish. 10, 58-87 (2009).

343 7. Sibert, J., Hampton, J., Kleiber, P. \& Maunder, M. Biomass, size, and trophic status of top 344 predators in the Pacific Ocean. Science 314, 1773-1776 (2006).

345 8. Boyce, D. G., Tittensor, D. P. \& Worm, B. Effects of temperature on global patterns of tuna and 346 billfish richness. Mar. Ecol. Prog. Ser. 355, 267-276 (2008).

347 9. Worm, B. \& Tittensor, D. P. Range contraction in large pelagic predators. Proc. Natl. Acad. Sci. 108, 11942-11947 (2011). 
349 10. Pauly, D., Watson, R. \& Alder, J. Global trends in world fisheries: impacts on marine 350 ecosystems and food security. Philos. Trans. Biol. Sci. 360, 5-12 (2005).

351 11. Garrison, L. P. \& Link, J. S. Dietary guild structure of the fish community in the Northeast 352

12. Bulman, C., Althaus, F., He, X., Bax, N. J. \& Williams, A. Diets and trophic guilds of demersal 354 fishes of the south-eastern Australian shelf. Mar. Freshw. Res. 52, 537-548 (2001).

355

15. Watson, R. A. A database of global marine commercial, small-scale, illegal and unreported fisheries catch 1950-2014. Sci. data 4, 170039 (2017).

16. Spalding, M. D. et al. Marine ecoregions of the world: a bioregionalization of coastal and shelf areas. Biosci. 57, 573-583 (2007).

17. Branch, T. A. et al. The trophic fingerprint of marine fisheries. Nature 468, 431-435 (2010).

18. Ricard, D., Minto, C., Jensen, O. P. \& Baum, J. K. Examining the knowledge base and status of commercially exploited marine species with the RAM Legacy Stock Assessment Database. Fish Fish. 13, 380-398 (2012). 
368 19. Sumaila, U. R., Marsden, A. D., Watson, R. \& Pauly, D. A global ex-vessel fish price database: 369 construction and applications. J. Bioeconomics 9, 39-51 (2007).

370 20. Suess, E. Particulate organic carbon flux in the oceans-surface productivity and oxygen $371 \quad$ utilization. Nature 288, 260-263 (1980).

372 21. Pomeroy, L. R. \& Deibel, D. O. N. Temperature regulation of bacterial activity during the spring 373 bloom in Newfoundland Coastal Waters. Science 233, 359-361 (1986).

374 22. Laws, E. A., Falkowski, P. G., Smith, W. O., Ducklow, H. \& McCarthy, J. J. Temperature effects on export production in the open ocean. Global Biogeochem. Cycles 14, 1231-1246 (2000).

23. Lutz, M. J., Caldeira, K., Dunbar, R. B. \& Behrenfeld, M. J. Seasonal rhythms of net primary production and particulate organic carbon flux to depth describe the efficiency of biological

24. Dunne, J. P., Armstrong, R. A., Gnanadesikan, A. \& Sarmiento, J. L. Empirical and mechanistic models for the particle export ratio. Global Biogeochem. Cycles 19, GB4026 (2005).

25. Tittensor, D. P. et al. Global patterns and predictors of marine biodiversity across taxa. Nature 466, 1098-1101 (2010).

26. Mackintosh, N. A. The pattern of distribution of the Antarctic fauna. Proc. R. Soc. B. Biol. Sci. 152, 624-631 (1960).

27. Kaschner, K., Tittensor, D. P., Ready, J., Gerrodette, T. \& Worm, B. Current and future patterns of global marine mammal biodiversity. PLoS One 6, e19653 (2011). 
28. Davidson, L. N. K., Krawchuk, M. A. \& Dulvy, N. K. Why have global shark and ray landings declined: improved management or overfishing? Fish Fish. 17, 438-458 (2016).

29. Drapeau, L., Pecquerie, L., Fréon, P. \& Shannon, L. J. Quantification and representation of potential spatial interactions in the southern Benguela ecosystem. African J. Mar. Sci. 26, 141159 (2004).

30. Brodeur, R. D., Buchanan, J. C. \& Emmett, R. L. Pelagic and demersal fish predators on juvenile and adult forage fishes in the Northern California Current: spatial and temporal variations. CalCOFI Rep. 55, 96-116 (2014).

31. McDaniel, J., Piner, K., Lee, H. H. \& Hill, K. Evidence that the migration of the northern subpopulation of Pacific Sardine (Sardinops sagax) off the west coast of the United States is age-based. PLoS One 11, e0166780 (2016).

32. Varpe, Ø., Fiksen, Ø. \& Slotte, A. Meta-ecosystems and biological energy transport from ocean to coast: the ecological importance of herring migration. Oecologia 146, 443 (2005).

33. Killen, S. S. et al. Ecological influences and morphological correlates of resting and maximal metabolic rates across teleost fish species. Am. Nat. 187, 592-606 (2016).

34. Watanabe, Y. Y., Goldman, K. J., Caselle, J. E., Chapman, D. D. \& Papastamatiou, Y. P. Comparative analyses of animal-tracking data reveal ecological significance of endothermy in fishes. Proc. Natl. Acad. Sci. 112, 6104-6109 (2015).

35. Stock, C. A. et al. Reconciling fisheries catch and ocean productivity. Proc. Natl. Acad. Sci. 114, E1441-E1449 (2017). 
408 36. Brander, K. M. Global fish production and climate change. Proc. Natl. Acad. Sci. 104, 19709$409 \quad 19714(2007)$.

410 37. Capotondi, A., Alexander, M. A., Bond, N. A., Curchitser, E. N. \& Scott, J. D. Enhanced upper ocean stratification with climate change in the CMIP3 models. J. Geophys. Res. Ocean. 117, C04031 (2012).

38. Sarmiento, J. L. et al. Response of ocean ecosystems to climate warming. Global Biogeochem. Cycles 18, GB3003 (2004).

39. Richardson, A. J. \& Schoeman, D. S. Climate impact on plankton ecosystems in the Northeast Atlantic. Science 305, 1609-1612 (2004).

40. Behrenfeld, M. J. et al. Climate-driven trends in contemporary ocean productivity. Nature 444, $752-755$ (2006).

41. Pauly, D. \& Zeller, D. Sea Around Us concepts, design and data. (2015). www.seaaroundus.org

42. Froese, R. \& Pauly, D. FishBase. www.fishbase.org (2016).

43. Compagno, L. J. V. Pelagic elasmobranch diversity. Ch. 3 in Sharks of the open Ocean: biology, fisheries and conservation ed. Camhi, M. D., Pikitch, E. K. \& Babcock, E. A. (Blackwell Publ.

44. Behrenfeld, M. J. \& Falkowski, P. G. Photosynthetic rates derived from satellite-based 425 chlorophyll concentration. Limnol. Oceanogr. 42, 1-20 (1997). 
Marine Ecosystems. PLoS One 7, e28945 (2012).

428

429

430

431

432

433

434

435

436

437

438

439

440

441

442

443

444

445

446

46. Morel, A. \& Berthon, J.-F. Surface pigments, algal biomass profiles, and potential production of the euphotic layer: relationships reinvestigated in view of remote-sensing applications. Limnol. Oceanogr. 34, 1545-1562 (1989).

47. Martin, J. H., Knauer, G. A., Karl, D. M. \& Broenkow, W. W. VERTEX: carbon cycling in the northeast Pacific. Deep Sea Res. Part A. Oceanogr. Res. Pap. 34, 267-285 (1987).

48. Amante, C. \& Eakins, B. ETOPO1 1 arc-minute global relief model: procedures, data sources and analysis. (2009).

49. Ward, C. L., McCann, K. S. \& Rooney, N. HSS revisited: multi-channel processes mediate trophic control across a productivity gradient. Ecol. Lett. 18, 1190-1197 (2015).

50. Richardson, K., Visser, A. W. \& Pedersen, F. B. Subsurface phytoplankton blooms fuel pelagic production in the North Sea. J. Plankton Res. 22, 1663-1671 (2000).

51. Schulien, J. A., Behrenfeld, M. J., Hair, J. W., Hostetler, C. A. \& Twardowski, M. S. Verticallyresolved phytoplankton carbon and net primary production from a high spectral resolution lidar. Opt. Express 25, 13577-13587 (2017).

52. Jónasdóttir, S. H., Visser, A. W., Richardson, K. \& Heath, M. R. Seasonal copepod lipid pump promotes carbon sequestration in the deep North Atlantic. Proc. Natl. Acad. Sci. 112, 12122$12126(2015)$.

53. Davison, P. C., Checkley, D. M., Koslow, J. A. \& Barlow, J. Carbon export mediated by mesopelagic fishes in the northeast Pacific Ocean. Prog. Oceanogr. 116, 14-30 (2013). 
447 54. Siegel, D. A. et al. Global assessment of ocean carbon export by combining satellite 448 observations and food-web models. Global Biogeochem. Cycles 28, 181-196 (2014).

449 55. Belkin, I. M. Rapid warming of large marine ecosystems. Prog. Oceanogr. 81, 207-213 (2009).

450 56. Jennings, S. \& Collingridge, K. Predicting consumer biomass, size-structure, production, catch 451 potential, responses to fishing and associated uncertainties in the world's marine ecosystems. $452 \quad$ PLoS One 10, e0133794 (2015).

453 57. Smithson, M. \& Verkuilen, J. A better lemon squeezer? Maximum-likelihood regression with $454 \quad$ beta-distributed dependent variables. Psychol. Methods 11, 54 (2006).

455 58. South, A. rworldmap: A new R package for mapping global data. The R Jour. 3, 35-43 (2011) 


\section{Acknowledgement}

457 We thank NS Jacobsen for his help with the RAM stock assessment database, CA Stock for advice on 458 the energy fluxes and UR Sumaila for making the global fish prices available. PDvD, ML, KHA 459 conducted the work within the Centre for Ocean Life, a VKR center of excellence supported by the 460 Villum Foundation. PDvD received funding from the People Programme (Marie Curie Actions) of the 461 European Union's Seventh Framework Programme (FP7/2007-2013) under REA grant agreement no 462609405 (COFUNDPostdocDTU). ML is supported by a VILLUM young investigator grant (13159). 463 RAW acknowledges support from the Australian Research Council (Discovery project DP140101377).

464 Author contributions:

465 PDvD, ML, BRMK, KHA conceived the study. RAW contributed with fisheries landings data. PDvD 466 performed the research with support of ML and KHA. PDvD, ML and KHA wrote the manuscript. All 467 authors contributed to interpretation of the results and commented on the manuscript.

\section{Author information:}

469 The authors declare no competing financial interests. Correspondence and requests for materials should 470 be addressed to PDvD (pdvd@aqua.dtu.dk) 
Figure legends

472 Figure 1. Conceptual figure illustrating the competitive interactions between large pelagic specialists and large demersal generalists that feed on smaller pelagic and/or demersal fish and invertebrates. The smaller pelagic and demersal fish feed on zooplankton or zoobenthos. Illustration by H. van Someren Gréve.

Figure 2. Average weight fraction of large pelagic fish compared to large demersal fish in fisheries landings between 1970 and 2014. Large pelagic fish are the dominant group of fish in most tropical and subtropical areas, whereas large demersal fish are dominant in temperate regions and the exclusive group at the poles. Grey ecoregions in the map are excluded from the analysis due to limited data availability (see method section). The boxplots show the ecoregions $(n=217)$ in bins of 5 degrees latitude, the midline of the box shows the median of the data, the limits of the box show the first and third quartile and the whiskers extend to a maximum of 1.5 times the interquartile range. The line is derived with a loess smoother.

Figure 3. Relationships between the fraction of large pelagic fishes in fisheries landings and the ratio between the fraction of net primary production (NPP) that remains in the photic zone $\left(F_{\text {photic }}\right)$ versus the fraction that reaches the seabed $\left(F_{\text {seabed }}\right)$ for all ecoregions with available data $(\mathbf{n}=\mathbf{2 1 7})$. Large demersal fish are dominant at approximately equal pelagic - benthic NPP ratios, while pelagic fish are dominant in areas where a high fraction of NPP remains in the photic zone (and/or where a low fraction of NPP reaches the seabed) (generalized additive model, p-value $<0.001$, deviance explained $=68 \%$ ). The fit is indicated by the solid line, the grey area shows the $95 \%$ confidence interval. Fish illustrations by H. van Someren Gréve. 
492 Figure 4. Predictions of the dominance of large pelagic specialists or demersal generalists across 493 marine ecoregions using a food-web model. a, Map of the predicted weight fraction large pelagic 494 specialists compared to demersal generalists in the food-web model based on region-specific energy 495 fluxes. b, Relationship between the fraction large pelagic fish in fisheries landings data and food-web 496 model for each ecoregion $\left(y=0.04+0.92 x_{1}, \mathrm{r}^{2}=0.58, \mathrm{p}\right.$-value $\left.<0.001\right)$, coloured points correspond to 497 ecoregions with a large difference $(>0.33)$ between the model predictions and the data. c, Map of all 498 ecoregions with a large difference $(>0.33)$ between the fraction large pelagic fish in fisheries landings 499 and the model, following (4b). Grey ecoregions are excluded from the analysis due to limited data 500 availability. Fish illustrations by H. van Someren Gréve. 